\title{
WHAT WE ARE DOING ABOUT SEISMIC SEA WAVES
}

\author{
by
}

\author{
Rear Admiral $\mathrm{H}$. Arnold Karo, Director \\ Coast and Geodetic Survey \\ U. S. Department of Commerce
}

I am glad to have this opportunity to participate in this section of the Sixth Conference on Coastal Engineering. My remarks to the distinguished group of engineers and scientists assembled here today will emphasize a phase of the work of the Coast and Geodetic Survey of the United States Department of Commerce pertinent to one of the problems encountered in coastal engineering.

I should like to mention the observance of our 150 years of service to the Nation, and that we are nearing the end of our year-long celebration of our Sesquicentennial year. In this long history of the Bureau in surveying and charting the coastal waters of the United States and possessions, our work has always been closely associated with the type of engineerıng activities with which you are identified.

Successlve hydrographic and topographic surveys of our coastal regions furnish basic data essential in studying changes in coastline and adjacent underwater topography; geodetic surveys provide the framework upon which all other survey work is based, and serve in developing construction plans for large-scale improvement projects; our geomagnetic work is being intensified during the International Geophysical Year in support of United States participation with some 60 nations; our tidal surveys and seismological investigations will be emphasized in discussing the subject selected for detailed consideration on this occasion.

The seismic sea wave is one of the forces of nature that has demonstrated on many occasions its ability or potential for great destruction. Earthquakes spawn these destructive seismic sea waves and the science of seismology is therefore basic to the engineering and related measures required in establishing effective safeguards .

The Coast and Geodetic Survey is uniquely qualified to carry on this type of activity. The solution which we have developed for es tablishing effective safeguards involves the use of seismographs, tide gages, seismic sea wave detectors, and an effective communications system to alert potential disaster areas. Rapid dissemination of due warning to inhabitants of the potential danger areas is also essential 


\section{COASTAL ENGINEERING}

to an effective system.

The selsmic sea wave, or tsunami, the Japanese term often user to 1dentify this phenomenon of nature, demonstrated its great capacity for destruction as recently as March 9, 1957. Traveling as fast as a jet airplane, the huge series of waves struck the Hawaiian Islands with a blow having an intensity proportional to the displacement which occurred on the earth's crust 2200 miles away in the Aleutian Trench ne: Amukta Pass. For the first time we were provided a first hand, eye witness account of a major sea wave as seen from a submarine resting in a small harbor in the path of the surging sea. There was never a more graphic example of nature's potential for violence.

The USS WAHOO was lying to for the week end in Nawiliwili Harbor on the Island of Kauai in the Hawaiians. This small port is on the protected side of Kauai for a wave approaching from the north. The first indication to the crew of the WAHOO of the arrival of the killer wave was a draining of the harbor, lowering the water level approximately five feet. This lasted about one or two minutes and was followed immediately by the first wave, which refilled the harbor in less than a minute.

Although the currents during the initial wave did not reach alarming proportions, the rapid shift of water was disquieting to the crew, to say the least. After a slight pause the water rapidly receded a second time, but came roaring back in a few moments as the second wave hit. This caused a change in water level of about ten feet in less than a minute.

The tremendous rise in water increased the harbor current to great proportions. The water rose relentlessly, submerged buoys, and set up a giant whirlpool action measuring about 300 yards in diame in the harbor basin. The water receded just as quickly as it had arriv with a rush which emptied the channel, accelerating the whirlpool action. The currents around the edge of the jetty on the inboard end of the channel increased to an estimated $18 \mathrm{knots,}$ which resulted in the channel becoming a boiling mass of foaming water.

Cross currents generated in the main channel continually fought the main ship stream assisted by a vast number of whirlpools and eddi In areas where the current was strongest the water was sucked away from the beach so as to expose land actually lower than the level of the main body of water. Subsequent waves of varying degrees of intensity acted in exactly the same manner. The period between the waves in the basin was irregular with short intermittent periods of relief, but after the initial onslaught the channel outside the jetty was a mass of cross currents which did not completely subside until several 


\section{WHAT WE ARE DOING ABOUT SEISMIC SEA WAVES}

hours after the last wave had receded. The tide continued to surge inside the port for some time after the actual sea wave action stopped. These surges were rather gradual, continually decreasing in force, although it was six or seven hours before the harbor calmed down to normal conditions.

This furst-hand account verified the fact that a small harbor with a narrow funneling channel, although not directly exposed, is particularly vulnerable to sea waves of this type. While the seismic sea wave in the open sea is relatively small in height, the rise of water in a harbor will vary tremendously, depending upon physiographical conditions. We have known that height at point of origin or at some intermediate stage of its travel does not indicate the extent or power of a sea wave.

The unbelievable current speeds generated in restricted channels in just a matter of minutes and the fact that a current under these conditions will reverse direction completely in less than two or three minutes at the peak of intensity, were verified by this first-hand account. Those who had this unique experience described the appearance of the wave as it entered the harbor as very similar to rapids in a river, having many eddy currents and considerable turbulence.

The entire perimeter of the north Pacific Ocean is an active seismic area, making the Hawalians and other islands of the Pacific especially vulnerable. In fact, it is possible for seismic sea waves to reach Hawali from all points of the compass. Since 1819 , about 40 such waves have been recorded, although many of them resulted in very little damage.

The last truly great disaster in the Hawailan Islands occurred on April 1, 1946, from the major seismic sea wave which was generated by a tremendous crustal movement along the northern slope of the Aleutian Trench south of Unimak Island. The violent earthquake setting off this movement was recorded on selsmographs all over the world. The devastating wave originated at the epicenter of the earthquake simultaneously with the seismic disturbance.

The series of destructive waves thus generated raced across the entire Pacific Ocean. Scotch Cap Lighthouse located on the western extremity of Unimak Island about 93 miles from the origin of the disturbance and towering 92 feet above high water was completely destroyed and five men were killed. The waves were recorded along the shores of North and South America, reaching Valparaiso, Chile in a little over eighteen hours. They were even recorded feebly in Sydney, Australia, 6700 miles away. They rushed southward at an average speed of 490 miles per hour, reaching the shores of the Hawaiian 


\section{COASTAL ENGINEERING}

Islands in about four and a half hours .

The coastal areas were submerged by a wall of water rising mor than fifty feet above the high-water shoreline, and rushed inland for more than a quarter of a mile. This was the most destructive of all waves in the history of the Islands. The loss of life reached 173; many more persons were seriously injured, and property damage amounted to 25 million dollars. The waves struck on all sides of the Islands, but their size and violence on reaching shore varied greatly from place to place, depending on the topography and other local features.

This variation ranged from two feet or less to a maximum of 55 feet. The violence of the onslaught ranged from gentle rises and falls almost entirely free from turbulence, to raging torrents. The variatic in height reached by the water was determined by the following factors (1) position of the coast in relation to the direction of wave origin; (2) shape of the island; (3) submarine topography; (4) presence or absence coral reefs; (5) exposure of the coast to storm waves; and (6) shorelint figuration and topography.

Variation in the turbulence of the waves as they rose over the coast was related partly to the varying height of water. This was due to the fact that the greater height of water piled against the shore re sulted in a steeper hydraulic gradient with increased rapidity of inland flow of water. This was particularly true in areas where the water surged over a barrier. Likewise, greater depth of water on shore resulted in a steeper gradient and more violent runback to the ocean durj wave troughs. Generally, in places where the water rose more than twenty feet the effects of the surge were violent.

In general, the waves were much more severe on the north shor facing the oncoming waves. The receding waters produced strong bac] water which caused most of the violent damage. The sea at the time was running moderately heavy and in some exposed areas wind-produc storm waves came in on the crests of the seismic sea waves to increase considerably their destructive force.

Well developed reefs or shoal areas reduced markedly the inten sity of wave assault on shores thus protected. The northern coast of Oahu, for instance, has a better developed reef pattern than the north coast of any of the other islands. Therefore, the average height reacl by the water along the northern coast of Oahu was correspondingly les than along the northern shore of any other of the larger islands, excer Lanai which is well protected on the north by Molokai. Reefs are especially effective in reducing the size and intensity of the waves where channels or lagoons of greater depth lie between the shoalest part of 


\section{WHAT WE ARE DOING ABOUT SEISMIC SEA WAVES}

the reef and the shore. The great barrier reef of Australia, together with the shielding islands of Melanesia to the northeast, afford a large measure of protection to the Australian coast. Similar protection is produced by other effects, however, such as in the case of a small bay on Hawaii whose entrance is nearly blocked by a ridge of lava rising nearly to or just above sea level. Hydrographic survey data by the Coast and Geodetic Survey are essential in studies of this type.

Shoreline protective measures such as breakwaters, if properly constructed, provide a measure of protection. The configuration of shoreline has a marked effect on the sea wave pattern. Waves are always largest at the heads of large funnel-shaped bays. In fact, coastal characteristics such as those existing at the Bay of Fundy greatly magnify ordinary tidal fluctuations.

Submarine topography plays a large part under such conditions due to the fact that the great wave length of seismic sea waves extends the movement of the water from the surface all the way to the ocean bottom. As the waves enter shallow water, interference of the bottom with wave motion causes an increase in the heights of the waves, a lessening of their speed, and a steepening of the wave fronts. We know that submarine ridges and valleys projecting from shore in the direction of wave origin are important factors in determing the height and violence of waves. The advance of waves moving toward shore parallel to the axial direction of the submarine ridge is retarded along the ridge more than in the deeper water on either side of it. Thus, the wave front becomes concave toward the head of the ridge and a large amount of wave energy builds up.

The speed of the waves is computed by the formula of the square root of the acceleration of gravity, multiplied by the depth of water. In oceanic depths of 2000 fathoms, the speed of the wave is about 370 knots, at 5000 fathoms they travel at about 580 knots, while at 10 fathoms the speed is greatly reduced to 26 knots.

The period of a seismic sea wave is more difficult to determine accurately. The tide gage record can seldom be read accurately to the minute, and in many cases the uncertainty covers several minutes. Moreover, the waves set up reflections or interference which cannot be accurately predicted. The period of the initial wave may vary from a few minutes to an hour or more. This diversity of periods 1s, of course, a confusing feature of the seismic sea wave.

Following the 1.946 disaster in the Hawaiian Islands, the Coast and Geodetic Survey or ganized the Seismic Sea Wave Warning System for detecting such waves immediately following their inception, and reporting them to potential disaster areas in the Pacific. This is a co- 


\section{COASTAL ENGINEERING}

operative undertaking, involving seismological observers for detecting and reporting large earthquakes in the Pacific area; tide stations 1ocated throughout the Pacific for detecting and reporting the resulting sea waves; a central station in Honolulu for receiving and evaluating reports, and alerting the central military and civil agencies, and rapid communications service between all stations and Honolulu.

Upon being alerted to the existence of a wave, the respective agencies put into operation previously developed plans for warning the civilian communities, shipping, and military bases. This warning system functioned for the first time to warn of the potentially destructive wave of November 4, 1952. Tide gage readings at Honolulu on this occasion reached a higher level than was recorded in 1946 , but the sea wave itself was not as destructive. In no cases did the waves of 1952 roll or dash up to the heights reached at some places by the great waves of 1946 . No lives were lost in 1952 and property loss was relatively small, which is of course attributable in large part to the successful operation of the Seismic Sea Wave Warning System. Last March, Secretary of Commerce Sinclair Weeks commended the Survey upon the successful operation of the system in giving sufficient advance warning to avert any loss of life follow ing the great seısmic sea wave of March 9th.

The system includes four Coast and Geodetic Survey seismological stations, each equipped with visible recorders and an alarm system to alert the observer. These stations are located at Fairbanks and Sitka, Alaska; Tucson, Arizona; and Honolulu. An additional observer is assigned to the Honolulu station which is the nerve center of the system and controls the operation of the system during an actual alert.

Additional seismological data are furnıshed by the University of California, California Institute of Technology, the United States Navy, Peruvian Huancayo observatory, the Japanese Central Meteorological Observatory, and the Manila observatory. Sixteen tide stations located throughout the Pacific are utilized to determine if a wave has been generated by a particular earthquake. Seismic sea wave detector have been installed at selected stations in the system as a precaution against delay in giving the alarm. This device alerts the tide observe to the arrival of large waves having the period of seismic sea waves. He can then examine his tide record and if necessary initiate a warnin message to Honolulu. Some of the Coast and Geodetic Survey stations are operated with the assistance of the Navy, Air Force, Civil Aeronautics Administration, University of California, and the government of American Samoa. All stations are serviced regularly by the Burea with the exception of one station located in the Canal Zone. 
The all-important communications services are furnished by the Navy, Army, Air Force, Civil Aeronautics Administration, Samoa, and the Peruvian Civil Aviation Corporation. Others at various places have made important contributions to the success of this undertaking. For example, the sheriff of Del Norte County in Cal ifornia makes available telephone service between his office and the Naval Communications station in San Francisco and the tide observer at our Crescent City tide station. Valuable assistance through unselfish cooperation of many others too numerous to mention, insures the successful operation of the warning system.

In the initial planning of the system, 1t was realized that a graphic method of rapidly determing the time of arrival of a wave in the central Pacific was an urgent requirement. To meet this need the Survey constructed a special chart for the Pacific area from which the travel tıme to Honolulu of a seismic sea wave could be readily determined. This chart consisted of a series of more or less concentric circles overprinted in red on a specially constructed chart of the Pacific Ocean. The encircling lines were spaced to represent hourly and half-hourly distances from Honolulu in sea wave travel time. In order to visualize the probable paths of wave travel, broken lines are made to radiate from Honolulu on great circle courses. Travel times were computed along the great circle paths in various directions from Honolulu. Each path was subdivided into segments of 120 nautical miles, and the travel times were computed in hours for each section.

In computing the times along the paths it was found that in some instances great circle courses passed over units of land or covered areas of lesser depth than in adjacent areas. Since a seismic sea wave advances more rapidly in deep water it was necessary to compute travel times along combinations of arcs of two or more intersecting great circles. This factor explains the irregularities in time curves which necessitated computation of additional paths to fully develop the bathymetric pattern.

At the request of Civil Defense authorities of the Pacific coast states, the warning system was extended this year to include predictions for the shores of California, Oregon, and Washington. This extension of the warning system required publication of five additional travel time charts which have been issued for selected areas along the Pacific coast.

Of particular interest in coastal engineering is the design of structures to withstand tremendous wave assault, and in the design and development of protective coastal installations. Structural damage has been at a minimum where buildings have been constructed 


\section{COASTAL ENGINEERING}

of reinforced concrete. Damage has always been heaviest to the buildj using light construction as is customary in the Hawaiian Islands. Dam to roads and railroads has been mostly of a nature common in any floo The foundations of bridges are particularly vulnerable, and extensive damage has been reported in the past. Piers withstand the waves well and most breakwaters survive with slight damage. Seawalls, when we constructed, are usually not materially damaged.

Coastal erosion due to sea waves is in general not as easy to determine as the damage to structures. Beaches are subject to some damage, as might be expected, however all beaches are subject to change during ordinary storms. This is especially true of the Hawaiia Islands where the distinct difference between wind and current directions during the stormy season results in considerable change, conforming to a pronounced annual cycle. Accurate surveys of the shoreline and intensive development of the adjacent coastal waters are essential in planning and developing protective measures.

The Coast and Geodetic Survey has been engaged in making the intensive topographic, hydrographic, and other surveys basic to this problem for well over one hundred years. The vast reservolr of precise facts which we have accumulated concerning the coastal regions of our country increases in importance with each successive decade. Additions are being constantly made to this storehouse of knowledge, both in quantity and quality, through intensive application of modern electronic techniques in refining and extending our basic operations.

In conclusion, I should like to re-emphasize the contributions of the Coast and Geodetic Survey to the seismic sea wave problem. Through intelligent utili zation of our wealth of coastal data, we are able to supply the answers to the basic questions, "What causes a seismic sea wave"", "How fast does it travel?", and "Where does it originate?". This rather specialized application of our knowledge and resources is in keeping with our fundamental policy of safeguarding human life and property at sea, on land, and in the air. 